\title{
Effect of dietary quebracho tannin extract on milk fatty acid composition in cows
}

\author{
Anika Henke, ${ }^{*}$ Edwin Westreicher-Kristen, ${ }^{* 1}$ Joachim Molkentin, $\dagger$ Uta Dickhoefer,‡ Karin Knappstein, $\dagger$ \\ Mario Hasler, § and Andreas Susenbeth* \\ *Institute of Animal Nutrition and Physiology, Christian-Albrechts-Universität zu Kiel, 24118 Kiel, Germany \\ †Department of Safety and Quality of Milk and Fish Products, Max Rubner-Institute, 24103 Kiel, Germany \\ łInstitute of Agricultural Sciences in the Tropics, Universität Hohenheim, 70599 Stuttgart, Germany \\ §Lehrfach Variationsstatistik, Christian-Albrechts-Universität zu Kiel, 24118 Kiel, Germany
}

\begin{abstract}
The aim of this study was to examine the capacity of quebracho tannin extract (QTE) to modulate the fatty acid (FA) profile in the milk fat of cows. Fifty Holstein cows yielding $33.2 \pm 8.2 \mathrm{~kg} / \mathrm{d}$ of milk were divided into 2 groups. The cows were fed a basal diet with a forage-concentrate ratio of 66:34 on a dry matter (DM) basis. Diets tested were control (CON, basal diet without QTE) and basal diet plus 15 or $30 \mathrm{~g}$ of QTE $/ \mathrm{kg}$ of $\mathrm{DM}$ (QTE $\mathrm{Q}_{15}$ and $\mathrm{QTE}_{30}$, respectively). Two treatments could be tested simultaneously and were arranged along 6 periods. The milk FA profile was characterized by increments in the proportion of linoleic (LA) and $\alpha$-linolenic acid ( $\alpha$-LNA) $\left(\mathrm{QTE}_{15}=10\right.$ and $6.1 \%$; $\mathrm{QTE}_{30}=28$ and $25 \%$, respectively) compared to CON, which might indicate reduced ruminal biohydrogenation $(\mathrm{BH})$ of both dietary LA and $\alpha$-LNA. Vaccenic acid (VA) in the milk fat was reduced $\left(\mathrm{QTE}_{15} 8.9 \%\right.$ and $\mathrm{QTE}_{30} 12 \%$ ) compared to CON, which may be linked to inhibited BH of LA and $\alpha$-LNA. Rumenic acid (RA), a conjugated LA (cis-9,trans-11 conjugated linoleic acid) and an important human health promoter, was unfortunately decreased $\left(\mathrm{QTE}_{15} 8.3 \%\right.$ and $\mathrm{QTE}_{30} 16 \%$ ) in the milk compared with CON, probably because of inhibited ruminal BH of LA. However, reduced RA in the milk was probably due to reduced availability of VA produced in the rumen and the consequently low VA available to be desaturated to RA in the mammary gland by $\Delta^{9}$-desaturase. The proportions of total polyunsaturated FA were increased with $\mathrm{QTE}_{15}$ and $\mathrm{QTE}_{30}$ by 4.7 and $15 \%$ compared to CON, respectively, and the long-chain FA proportions were also increased
\end{abstract}

Received October 13, 2016.

Accepted April 6, 2017.

${ }^{1}$ Corresponding author: westreicher@aninut.uni-kiel.de
$\left(\mathrm{QTE}_{15} 2.0 \%\right.$ and $\left.\mathrm{QTE}_{30} 8.2 \%\right)$. Moreover, myristic and palmitic acid were reduced by $\mathrm{QTE}_{30}$ (9.6 and $3.3 \%$, respectively) compared to $\mathrm{CON}$, which also contributed to increasing the nutritional quality of milk because they are recognized to increase high-density lipoprotein in humans. Branched-chain FA in milk was reduced with QTE treatments, which indicates inhibited ruminal BH and microbial activity. In general, our findings suggest that dietary QTE have the potential to modulate FA profile of milk fat, and this effect is dosage dependent. Because QTE influenced the FA profile of milk fat both positively and negatively, further research is needed before concluding that QTE may improve the nutritional quality of cow milk fat in human diets.

Key words: condensed tannin, biohydrogenation, fatty acid profile, $\alpha$-linolenic acid

\section{INTRODUCTION}

Triacylglycerides with more than 400 different fatty acids (FA) (Månsson, 2008) are the main components of milk fat in cows. The FA are either synthesized de novo in the mammary gland or taken up from the blood (Chilliard et al., 2000), which contains FA that originate mainly from the diet, lipid metabolism of rumen microbes, and mobilized body fat (Stoop et al., 2009).

Microbial biohydrogenation (BH) of PUFA decisively influences the composition of milk fat. During ruminal $\mathrm{BH}$, linoleic acid (LA, cis-9,cis-12 C18:2), $\alpha$-linolenic acid ( $\boldsymbol{\alpha}$-LNA, cis-9,cis-12,cis-15 C18:3), and oleic acid (OA, cis-9 C18:1), as the main substrates of this process, are successively isomerized and hydrogenated to C18:2 and C18:1 isomers that may in turn be further saturated to stearic acid (SA, C18:0) (Shingfield et al., 2010). Condensed tannins may bind to rumen microbes or to their enzymes and may thereby also inhibit growth and activity of rumen microbes responsible for $\mathrm{BH}$ (Min et al., 2003). For instance, Buccioni et al. (2015) showed that condensed tannins from the heartwood of 
the quebracho tree (Schinopsis lorentzii and Schinopsis balansae) inhibit Butyrivibrio proteoclasticus, one of the bacterial species involved in ruminal $\mathrm{BH}$. The effects of condensed tannins on ruminal $\mathrm{BH}$ have been linked to an accumulation of the substrates LA, $\alpha$-LNA, or $\mathrm{OA}$ or their corresponding intermediates, as well as a corresponding increase in the proportions of PUFA, in the milk (Buccioni et al., 2015).

Quebracho tannin extract (QTE) as a commercial source of condensed tannins has been widely investigated in ruminant feeding. Overall, agreement exists that high levels of quebracho tannins have negative effects on rumen microbial activity. For instance, recent studies of Ahnert et al. (2015) and Henke et al. (2017) evaluated the effects of increasing levels of QTE on digestibility, nitrogen partitioning, microbial crude protein synthesis, and milk yield and composition. Both studies found that QTE inclusion of 15 and $30 \mathrm{~g} / \mathrm{kg}$ of DM in the diets of Holstein dairy cows (Henke et al., 2017) and 40 and $60 \mathrm{~g} / \mathrm{kg}$ of DM in the diets of rumencannulated heifers (Ahnert et al., 2015) decreases apparent total-tract digestibility of the fiber fractions and reduces urinary purine derivatives excretion. Fermentation in the rumen and microbial growth, activity, or both were suggested as probably being impaired by QTE. Although condensed tannins such as those in QTE are well known for these antinutritional effects at high doses in ruminants (Mueller-Harvey, 2006), they may increase PUFA content in the milk, which is considered positive from a human health point of view (Dewhurst et al., 2006). However, results in literature on the effects of QTE on FA profile in milk or rumen fluid of ruminants are inconclusive and quite limited (Kronberg et al., 2007; Toral et al., 2013; Buccioni et al., 2015). Although in vitro experiments show positive effects on rumen $\alpha$-ALA accumulation, in vivo studies seem to suggest no significant effect (Kronberg et al., 2007; Benchaar and Chouinard, 2009). Furthermore, one in vivo study with dairy ewes showed positive effects on milk vaccenic acid (VA, trans-11 C18:1) proportion ( $53 \mathrm{~g}$ of $\mathrm{QTE} / \mathrm{kg}$ of DM; Buccioni et al., 2015), but in another study, QTE did not affect milk VA (20 g of QTE $/ \mathrm{kg}$ of DM; Toral et al., 2013). Owing to the potential of quebracho tannins to positively modulate the FA profile of milk fat and the limited and contradictory information on the use of QTE to alter the $\mathrm{BH}$ process, further and more specific characterization of this additive through feeding trials under field conditions is required. Therefore, the aim of the present study was to examine the capacity of quebracho tannin (i.e., $15 \mathrm{~g}$ vs. $30 \mathrm{~g}$ of $\mathrm{QTE} / \mathrm{kg}$ of diet $\mathrm{DM}$ ) to modulate the milk FA profile of cows with a special focus on the FA related to ruminal $\mathrm{BH}$ : LA, $\alpha$-LNA, rumenic acid (RA, a CLA, cis-9,trans-11 C18:2), VA, SA, and OA.

\section{MATERIALS AND METHODS}

The animal study reported herein was performed in accordance with the animal welfare legislation and approved by the Animal Welfare Commission of the Ministry of Energy, Agriculture, Environment, and Rural Affairs of the federal state of Schleswig-Holstein in Germany (V312-72241.123-5). A special permit for feeding QTE to dairy cows in this experiment was granted by the competent authority for feed control, Landeslabor Schleswig-Holstein (LSH3212, dated April 9, 2012).

\section{Animals, Diets, and Experimental Design}

The data were derived from the trial described by Henke et al. (2017), which was conducted at the experimental farm Schädtbek of the Max Rubner-Institute (Dobersdorf, Germany). Fifty Holstein dairy cows, divided into 2 groups of 25 cows each, were used for this feeding trial. The average milk yield, BW, DIM, and number of lactations of the cows at the start of the experiment were $33.2 \pm 8.2 \mathrm{~kg} / \mathrm{d}, 637 \pm 58 \mathrm{~kg}$, $114 \pm 73 \mathrm{~d}$, and $2.3 \pm 1.6$ lactations, respectively. The cows were housed in a freestall barn, had free access to drinking water, and were offered the diets once a day at approximately $0600 \mathrm{~h}$ for ad libitum consumption. The cows were fed a basal diet of total mixed ration that contained (on DM basis) 34\% grass silage, 32\% maize silage, and $34 \%$ concentrate mixture (Table 1), and a mineral premix was added. The QTE (S. lorentzii, Silvafeed ByPro; Silvateam S.p.a., San Michele Mondovì, Italy) was a fine, red powder, containing $705 \mathrm{~g} /$ $\mathrm{kg}$ total phenols (tannic acid equivalents) according to the Folin-Ciocalteu method, and $157 \mathrm{~g} / \mathrm{kg}$ condensed tannins (leucocyanidin equivalents) determined with the HCl-butanol method described by Porter et al. (1986). Every morning before feeding, the extract was added to a mixer wagon and thoroughly mixed into the basal diet at levels of 15 or $30 \mathrm{~g} / \mathrm{kg}$ of DM. Hence, we created 3 dietary treatments: the control $(\mathbf{C O N}$, basal diet without QTE), the basal diet $+15 \mathrm{~g}$ of QTE $/ \mathrm{kg}$ of DM $\left(\mathbf{Q T E}_{15}\right)$, and the basal $+30 \mathrm{~g}$ of $\mathrm{QTE} / \mathrm{kg}$ of DM $\left(\mathbf{Q T E}_{30}\right)$. Because of technical limitations only 2 treatments could be tested simultaneously. Therefore, the 3 treatments were tested across 6 experimental periods. Details on experimental design are described in detail by Henke et al. (2017). Each period comprised $21 \mathrm{~d}$ with a 13-d adaptation phase followed by an 8-d sampling phase, and cows were the experimental unit.

\section{Sample Collection, Preparation, and Analysis}

Diets. Details on diet sampling and analysis of crude ash, ether extract, $\mathrm{CP}, \mathrm{NDF}, \mathrm{ADF}, \mathrm{ADL}$, and starch 
Schaarschmidt and Vaas (2009) and the experimental group as random factor. The pseudo-factor was composed of period $(\mathbf{P})$ and treatment and had 10 levels: (1) CON in $\mathrm{P} 1,(2) \mathrm{QTE}_{15}$ in $\mathrm{P} 2$, (3) $\mathrm{CON}$ in $\mathrm{P} 2$, (4) CON in P3, (5) $\mathrm{QTE}_{15}$ in $\mathrm{P} 3$, (6) $\mathrm{QTE}_{30}$ in $\mathrm{P} 4,(7) \mathrm{CON}$ in $\mathrm{P} 4,(8) \mathrm{CON}$ in $\mathrm{P} 5$, (9) $\mathrm{QTE}_{30}$ in $\mathrm{P} 5$, and (10) $\mathrm{CON}$ in $\mathrm{P} 6$. The correlations of the measurement values due to the several periods were taken into account by the model. To adjust the treatment effect, DIM and lactation number were included as covariates. The covariate lactation number was arranged in 4 categories: 1, 2, 3, or $\geq 4$ according to the respective lactation number of individual animals. The statistical mixed model used was the following:

$$
Y_{i j}=a_{i}+b \times x_{1}+c \times x_{2}+\gamma+e_{i j}
$$

where $Y_{i j}$ is the investigated variable, $a_{i}$ is the intercept per period and treatment, $b$ is the slope related to DIM $\left(x_{1}\right), c$ is the slope related to lactation number $\left(x_{2}\right), \gamma$ is the error term related to experimental group, $e_{i j}$ is the residual error, $i$ is the level of the pseudo-factor $(i=1$, $\ldots, \mathrm{n})$, and $j$ is the animal per level of the pseudo-factor $\left(j=1, \ldots, \mathrm{n}_{i}\right)$. Assuming all the cows have the same value of the covariate $(\mathrm{DIM}=178 \mathrm{~d}$, lactation number $=2.3$ ), we predicted values of the variables for each cow. These covariate values represent the average DIM and the average lactation number across all experimental cows and periods. Afterward, least squares means and standard errors per treatment were calculated from the predicted values of the variables per cow. Multiple contrast tests were applied to determine treatment effects (CON vs. QTE 15 vs. QTE ${ }_{30}$ ) according to Hothorn et al. (2008). Significant differences were declared at $P$ $<0.05$, and tendencies with $P$-values between 0.05 and 0.10 .

\section{RESULTS}

\section{Fatty Acid Composition of Diets}

The 3 experimental diets consisted of $4.91 \pm 0.11 \mathrm{~g}$ $\mathrm{SFA} / \mathrm{kg}$ DM, $7.75 \pm 0.60 \mathrm{~g}$ MUFA $/ \mathrm{kg}$ DM, and 11.9 $\pm 0.60 \mathrm{~g}$ of PUFA $/ \mathrm{kg}$ of DM (Table 1 ). Total SFA and MUFA consisted predominantly of palmitic acid (PA, C16:0, $3.25 \pm 0.07 \mathrm{~g} / \mathrm{kg}$ of DM) and $\mathrm{OA}(6.61 \pm 0.49$ $\mathrm{g} / \mathrm{kg}$ of DM). For all diets, PUFA was dominated by the LA $(6.90 \pm 0.22 \mathrm{~g} / \mathrm{kg}$ of DM) and $\alpha$-LNA $(4.93 \pm$ $0.40 \mathrm{~g} / \mathrm{kg}$ of DM). The total FA proportion was similar among the 3 experimental diets and averaged $24.6 \pm$ $0.97 \mathrm{~g} / \mathrm{kg}$ of DM $(24.8,23.5$, and $25.4 \mathrm{~g} / \mathrm{kg}$ of DM for $\mathrm{CON}, \mathrm{QTE}_{15}$, and $\mathrm{QTE}_{30}$, respectively).

\section{Fatty Acid Composition of Milk}

Sixty-seven individual FA in the milk fat were detected and are reported in Tables 2, 3 and 4. In general, palmitic acid, OA, myristic acid (MA, C14:0), and SA contributed the most to total FA content in the milk with average proportions over all 3 treatments of 26.8 , 20.6, 11.0, and $10.0 \mathrm{~g} / 100 \mathrm{~g}$ of FA, respectively. The proportions of $\mathrm{C} 4: 0, \mathrm{C} 6: 0, \mathrm{C} 8: 0, \mathrm{C} 10: 0, \mathrm{C} 12: 0, \mathrm{C} 15: 0$, cis-9 C14:1, cis-9 C16:1, trans-11 C18:1, and LA were between 1.0 and $3.5 \mathrm{~g} / 100 \mathrm{~g}$ of FA. Proportions between 0.01 and $1.00 \mathrm{~g} / 100 \mathrm{~g}$ of FA were detected for the remaining $52 \mathrm{FA}$. Both QTE dosages decreased the proportions of MA (11.0 and $10.8 \mathrm{~g} / 100 \mathrm{~g}$ of FA with $\mathrm{QTE}_{15}$ and $\mathrm{QTE}_{30}$, respectively) compared to CON $(11.2 \mathrm{~g} / 100 \mathrm{~g}$ of FA, Table 2). Similarly, the proportions of PA were lower with $\mathrm{QTE}_{30}(25.1 \mathrm{~g} / 100 \mathrm{~g}$ of FA) followed by $\mathrm{QTE}_{15}(27.4 \mathrm{~g} / 100 \mathrm{~g}$ of FA) and CON $(27.8 \mathrm{~g} / 100 \mathrm{~g}$ of FA). The proportions of SA were increased with both $\mathrm{QTE}_{15}$ and $\mathrm{QTE}_{30}$ when compared with CON, whereas those of C20:0 to C23:0 were only increased with $\mathrm{QTE}_{30}$ (Table 2). For odd-chain FA, only those from C5:0 to C11:0 and C17:0 were reduced with $\mathrm{QTE}_{30}$ compared to CON, whereas C13:0 and C15:0 were reduced with each increasing level of QTE in the diet. Between individual BCFA (Table 2), FA responded differently to QTE treatments. Proportion of iso C18:0 in the milk fat was reduced only with $\mathrm{QTE}_{30}$, whereas iso $\mathrm{C} 13: 0$, iso $\mathrm{C} 15: 0$ and iso $\mathrm{C} 16: 0$ proportions were similarly reduced with $\mathrm{QTE}_{15}$ and $\mathrm{QTE}_{30}$ compared to CON. But iso C14:0 was reduced with each increasing level of QTE in the diet. Among all presented SFA, only C10:0, C12:0 and C19:0 did not differ between treatments. The proportions of VA (Table 3 ) were lower with $\mathrm{QTE}_{15}(0.96 \mathrm{~g} / 100 \mathrm{~g}$ of $\mathrm{FA})$ and $\mathrm{QTE}_{30}(0.93$ $\mathrm{g} / 100 \mathrm{~g}$ of FA) compared to CON (1.06 g/100 g of FA), whereas the proportions of trans-10 C18:1 remained constant among treatments $(0.52 \mathrm{~g} / 100 \mathrm{~g}$ of FA). Furthermore, the proportions of OA (Table 3) were higher with $\mathrm{QTE}_{30}\left(21.6 \mathrm{~g} / 100 \mathrm{~g}\right.$ of FA) followed with $\mathrm{QTE}_{15}$ $(20.7 \mathrm{~g} / 100 \mathrm{~g}$ of FA) compared to CON $(20.2 \mathrm{~g} / 100 \mathrm{~g}$ of FA). The LA and $\alpha$-LNA (Table 4) increased with $\operatorname{QTE}_{15}\left(2.00\right.$ and $0.62 \mathrm{~g} / 100 \mathrm{~g}$ of FA) and $\mathrm{QTE}_{30}(2.32$ and $0.73 \mathrm{~g} / 100 \mathrm{~g}$ of FA, respectively) compared to CON (1.80 and $0.59 \mathrm{~g} / 100 \mathrm{~g}$ of FA, respectively). Both QTE dosages decreased the proportions of RA (0.49 and 0.45 $\mathrm{g} / 100 \mathrm{~g}$ of $\mathrm{FA}$ with $\mathrm{QTE}_{15}$ and $\mathrm{QTE}_{30}$, respectively) compared to CON $(0.53 \mathrm{~g} / 100 \mathrm{~g}$ of FA), whereas the proportions of trans-11,cis-15 C18:2 tended to be lower only with $\mathrm{QTE}_{30}$ compared with CON.

The effect of QTE on proportions of the different groups of milk FA is shown in Table 5. The proportions of SFA in milk fat were 65.9 and $64.9 \mathrm{~g} / 100 \mathrm{~g}$ of 
FA with $\mathrm{QTE}_{15}$ and $\mathrm{QTE}_{30}$, respectively, and slightly lower compared to CON (66.5 g/100 g of FA, Table 5). The proportions of MUFA and PUFA were higher and the ratios of SFA to unsaturated FA were lower with $\mathrm{QTE}_{15}$ and $\mathrm{QTE}_{30}$ compared to CON. The proportions of LCFA and MCFA in the milk fat were 40.9 and 47.3 $\mathrm{g} / 100 \mathrm{~g}$ of FA with CON, respectively. Both QTE dosages increased the proportions of LCFA and decreased the proportions of MCFA. Milk fat of cows receiving $\mathrm{QTE}_{15}$ and $\mathrm{QTE}_{30}$ contained lower proportions of BCFA (1.61 and $1.66 \mathrm{~g} / 100 \mathrm{~g}$ of $\mathrm{FA}$, respectively) compared to CON $(1.70 \mathrm{~g} / 100 \mathrm{~g}$ of FA).

\section{DISCUSSION}

As shown in our previous publication (Henke et al., 2017), dietary QTE did not affect feed intake but decreased the apparent total-tract digestibility of the fiber fractions and the urinary excretion of purine derivatives. Data for average milk yield and milk composition of this experiment have already been published elsewhere (Henke et al., 2017). Condensed tannins are well known for their inhibitory effect upon rumen microbes (Min et al., 2003), and therefore, their potential to impair ruminal BH (Jones et al., 1994). Inhibition of microbes can occur by condensed tannins forming complexes with microbial proteins (Jones et al., 1994), by microbial enzymes being inhibited, or by rumen microbes being deprived of substrates or metal ions (Smith et al., 2005). Results of our previously published study (Henke et al., 2017) suggested modified ruminal fermentation and microbial growth, activity, or both with $\mathrm{QTE}_{30}$, as indicated by reduced excretion of purine derivates. Thus, an influence of 15 or $30 \mathrm{~g}$ of QTE $/ \mathrm{kg}$ of DM on BH of dietary FA and therefore FA profile in milk fat could be expected. Because our aim was to evaluate the effect of QTE on BH of FA, only the most important FA related to ruminal $\mathrm{BH}$ are discussed in this article.

The LA and $\alpha$-LNA - the main substrates for BHshowed higher concentrations in the milk fat of cows fed $\mathrm{QTE}_{15}$ or $\mathrm{QTE}_{30}$ than those fed CON. Buccioni et al. (2015) reported that an LA-rich diet supplemented with $\sim 53 \mathrm{~g}$ of QTE/ $\mathrm{kg}$ of DM increased the concentrations of LA and $\alpha$-LNA in milk of ewes. Additionally, Kronberg et al. (2007) determined increasing concentrations of $\alpha$-LNA when flaxseed with QTE was incubated in rumen fluid in vitro for $24 \mathrm{~h}$. In tissues, LA is the

Table 2. Saturated fatty acid (FA) composition (least squares means \pm SE) of milk fat of cows on the control diet (CON) and at 2 levels of quebracho tannin extract (QTE, 15 or $30 \mathrm{~g} / \mathrm{kg}$ of DM)

\begin{tabular}{|c|c|c|c|c|c|c|}
\hline $\mathrm{FA}(\mathrm{g} / 100 \mathrm{~g}$ of $\mathrm{FA})$ & \multicolumn{3}{|c|}{ Treatment } & \multicolumn{3}{|c|}{$P$-value } \\
\hline C6:0 & $2.328 \pm 0.030$ & $2.319 \pm 0.052$ & $2.419 \pm 0.052$ & 0.90 & $<0.001$ & $<0.001$ \\
\hline $\mathrm{C} 7: 0$ & $0.033 \pm 0.001$ & $0.031 \pm 0.001$ & $0.028 \pm 0.001$ & 0.13 & $<0.001$ & 0.05 \\
\hline $\mathrm{C} 8: 0$ & $1.375 \pm 0.016$ & $1.377 \pm 0.029$ & $1.422 \pm 0.028$ & 0.98 & $<0.001$ & 0.01 \\
\hline C11:0 & $0.064 \pm 0.002$ & $0.062 \pm 0.003$ & $0.054 \pm 0.003$ & 0.34 & $<0.001$ & $<0.001$ \\
\hline C12:0 & $3.522 \pm 0.034$ & $3.508 \pm 0.062$ & $3.483 \pm 0.059$ & 0.88 & 0.31 & 0.82 \\
\hline iso C13:0 & $0.022 \pm 0.000$ & $0.020 \pm 0.000$ & $0.019 \pm 0.001$ & $<0.001$ & $<0.001$ & 0.16 \\
\hline C13:0 & $0.101 \pm 0.002$ & $0.094 \pm 0.004$ & $0.087 \pm 0.004$ & 0.01 & $<0.001$ & 0.05 \\
\hline iso C14:0 & $0.064 \pm 0.001$ & $0.057 \pm 0.001$ & $0.053 \pm 0.001$ & $<0.001$ & $<0.001$ & $<0.001$ \\
\hline C14:0 (myristic acid) & $11.18 \pm 0.062$ & $11.02 \pm 0.114$ & $10.81 \pm 0.106$ & 0.01 & $<0.001$ & 0.02 \\
\hline iso $\mathrm{C} 15: 0$ & $0.200 \pm 0.001$ & $0.183 \pm 0.002$ & $0.182 \pm 0.002$ & $<0.001$ & $<0.001$ & 0.90 \\
\hline anteiso $\mathrm{C} 17: 0$ & $0.431 \pm 0.003$ & $0.414 \pm 0.005$ & $0.445 \pm 0.005$ & $<0.001$ & 0.01 & $<0.001$ \\
\hline C17:0 & $0.495 \pm 0.003$ & $0.487 \pm 0.005$ & $0.475 \pm 0.005$ & 0.16 & $<0.001$ & 0.03 \\
\hline iso C18:0 & $0.057 \pm 0.001$ & $0.058 \pm 0.002$ & $0.047 \pm 0.002$ & 0.63 & $<0.001$ & $<0.001$ \\
\hline C18:0 (stearic acid) & $10.01 \pm 0.085$ & $10.25 \pm 0.152$ & $11.42 \pm 0.149$ & 0.01 & $<0.001$ & $<0.001$ \\
\hline C19:0 & $0.111 \pm 0.001$ & $0.110 \pm 0.003$ & $0.110 \pm 0.003$ & 0.84 & 0.85 & 1.00 \\
\hline $\mathrm{C} 20: 0$ & $0.185 \pm 0.001$ & $0.185 \pm 0.003$ & $0.209 \pm 0.003$ & 0.98 & $<0.001$ & $<0.001$ \\
\hline $\mathrm{C} 21: 0$ & $0.037 \pm 0.001$ & $0.036 \pm 0.002$ & $0.039 \pm 0.002$ & 0.19 & $<0.001$ & $<0.001$ \\
\hline $\mathrm{C} 22: 0$ & $0.063 \pm 0.003$ & $0.065 \pm 0.006$ & $0.074 \pm 0.006$ & 0.38 & $<0.001$ & $<0.001$ \\
\hline $\mathrm{C} 23: 0$ & $0.035 \pm 0.001$ & $0.035 \pm 0.001$ & $0.040 \pm 0.001$ & 0.56 & $<0.001$ & $<0.001$ \\
\hline C24:0 & $0.010 \pm 0.000$ & $0.013 \pm 0.000$ & $0.009 \pm 0.000$ & $<0.001$ & 0.27 & $<0.001$ \\
\hline
\end{tabular}


Table 3. Monounsaturated fatty acid (FA) composition (least squares means \pm SE) of milk fat of cows on the control diet (CON) and at 2 levels of quebracho tannin extract (QTE, 15 or $30 \mathrm{~g} / \mathrm{kg}$ of DM)

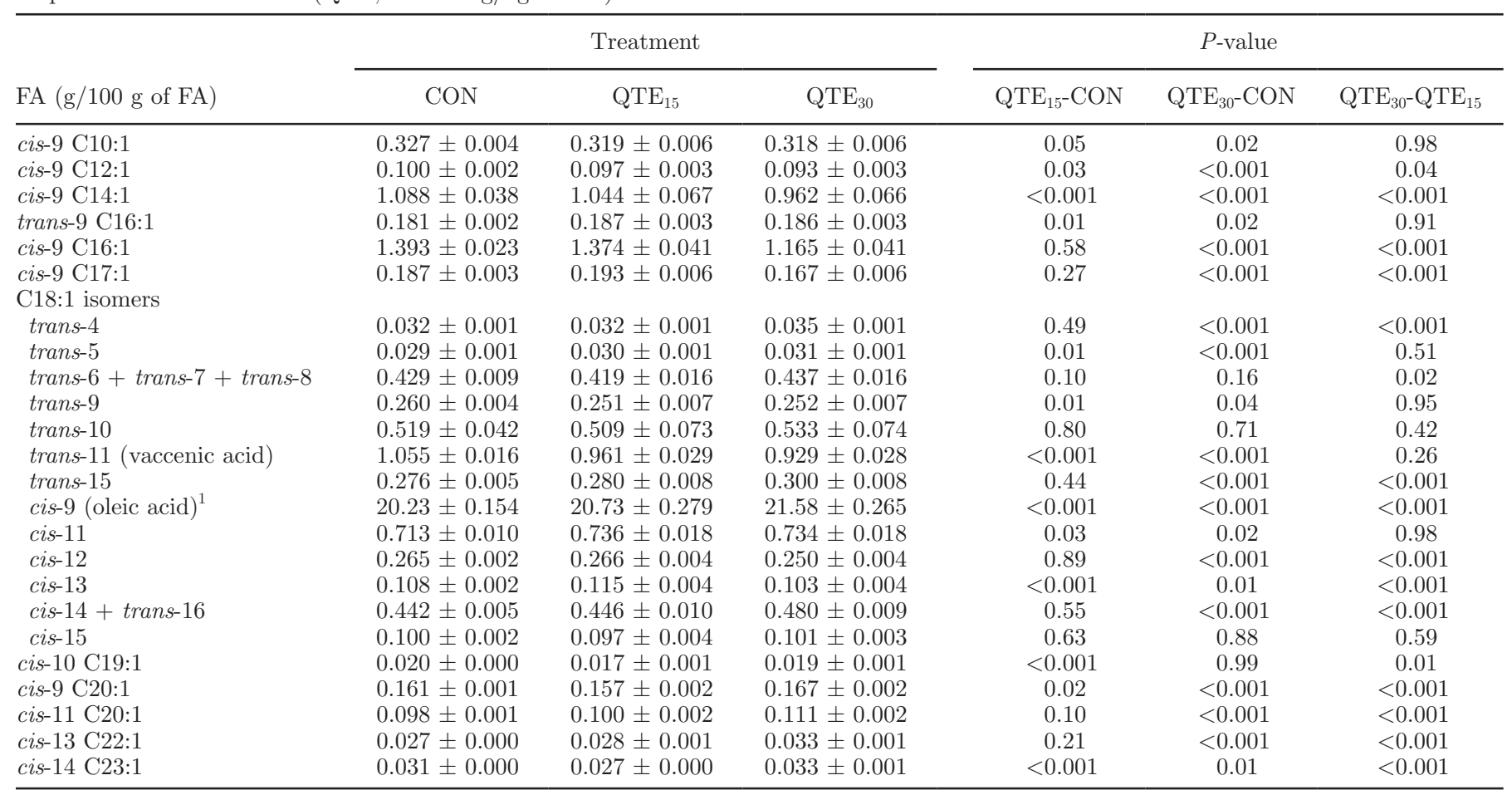

${ }^{1}$ Includes minor proportions of trans-12-14 C18:1 (<1.0 g/100 g of FA).

precursor of the very-long-chain FA arachidonic acid (cis-5,cis-8, cis-11,cis-14 C20:4) and eicosatrienoic acid (cis-8, cis-11,cis-14 C20:3), and $\alpha$-LNA is the precursor of eicosapentaenoic acid (cis-5,cis-8,cis-11,cis-14,cis-17
C20:5) and docosapentaenoic acid (cis-7,cis-10, cis13,cis-16,cis-19 C22:5) (Salem et al., 1999). Compared to CON, concentrations of arachidonic and docosapentaenoic acids were increased with $\mathrm{QTE}_{15}$ and $\mathrm{QTE}_{30}$,

Table 4. Polyunsaturated fatty acid (FA) composition (least squares means \pm SE) of milk fat of cows on the control diet (CON) and at 2 levels of quebracho tannin extract (QTE, 15 or $30 \mathrm{~g} / \mathrm{kg}$ of DM)

\begin{tabular}{|c|c|c|c|c|c|c|}
\hline \multirow[b]{2}{*}{$\mathrm{FA}(\mathrm{g} / 100 \mathrm{~g}$ of FA) } & \multicolumn{3}{|c|}{ Treatment } & \multicolumn{3}{|c|}{$P$-value } \\
\hline & $\mathrm{CON}$ & $\mathrm{QTE}_{15}$ & $\mathrm{QTE}_{30}$ & $\mathrm{QTE}_{15^{-}} \mathrm{CON}$ & $\mathrm{QTE}_{30^{-}} \mathrm{CON}$ & $\mathrm{QTE}_{30}-\mathrm{QTE}_{15}$ \\
\hline \multicolumn{7}{|l|}{ C18:2 isomers } \\
\hline trans -9, trans -12 & $0.016 \pm 0.001$ & $0.016 \pm 0.001$ & $0.015 \pm 0.001$ & 0.54 & 0.25 & 0.87 \\
\hline trans- 8, cis- $12+$ cis- 9, trans -13 & $0.429 \pm 0.006$ & $0.432 \pm 0.010$ & $0.438 \pm 0.010$ & 0.88 & 0.13 & 0.56 \\
\hline trans-8,cis-13 & $0.161 \pm 0.002$ & $0.164 \pm 0.004$ & $0.159 \pm 0.004$ & 0.27 & 0.61 & 0.12 \\
\hline cis-9,trans-12 & $0.083 \pm 0.001$ & $0.084 \pm 0.001$ & $0.089 \pm 0.001$ & 0.30 & $<0.001$ & $<0.001$ \\
\hline trans-11, cis- 15 & $0.135 \pm 0.002$ & $0.137 \pm 0.004$ & $0.130 \pm 0.004$ & 0.70 & 0.08 & 0.03 \\
\hline cis-9,cis-12 (linoleic acid) & $1.800 \pm 0.013$ & $1.991 \pm 0.024$ & $2.315 \pm 0.024$ & $<0.001$ & $<0.001$ & $<0.001$ \\
\hline cis-9,trans-11 (rumenic acid, CLA) & $0.532 \pm 0.008$ & $0.488 \pm 0.014$ & $0.449 \pm 0.014$ & $<0.001$ & $<0.001$ & $<0.001$ \\
\hline \multicolumn{7}{|l|}{ C18:3 isomers } \\
\hline cis-6, cis-9, cis-12 & $0.020 \pm 0.001$ & $0.018 \pm 0.001$ & $0.022 \pm 0.001$ & 0.06 & 0.29 & 0.02 \\
\hline cis-9,cis-12,cis-15 ( $\alpha$-linolenic acid $)$ & $0.586 \pm 0.004$ & $0.622 \pm 0.007$ & $0.734 \pm 0.007$ & $<0.001$ & $<0.001$ & $<0.001$ \\
\hline cis-11,cis-14 C20:2 & $0.024 \pm 0.000$ & $0.024 \pm 0.001$ & $0.030 \pm 0.001$ & 1.00 & $<0.001$ & $<0.001$ \\
\hline cis- 8, cis- 11, cis- $14 \mathrm{C} 20: 3^{1}$ & $0.077 \pm 0.001$ & $0.077 \pm 0.002$ & $0.090 \pm 0.002$ & 0.97 & $<0.001$ & $<0.001$ \\
\hline cis-5,cis-8,cis-11,cis-14 C20:4 $4^{2}$ & $0.099 \pm 0.001$ & $0.104 \pm 0.002$ & $0.111 \pm 0.002$ & $<0.001$ & $<0.001$ & $<0.001$ \\
\hline cis-5,cis-8,cis-11,cis-14,cis-17 C20:5 $5^{3}$ & $0.089 \pm 0.001$ & $0.090 \pm 0.002$ & $0.098 \pm 0.001$ & 0.74 & $<0.001$ & $<0.001$ \\
\hline cis- 7, cis- 10, cis- 13, cis- 16, cis-19 C $22: 5^{4}$ & $0.083 \pm 0.001$ & $0.088 \pm 0.001$ & $0.090 \pm 0.001$ & $<0.001$ & $<0.001$ & 0.75 \\
\hline
\end{tabular}

\footnotetext{
${ }^{1}$ Eicosatrienoic acid.

${ }^{2}$ Arachidonic acid

${ }^{3}$ Eicosapentaenoic acid.

${ }^{4}$ Docosapentaenoic acid.
} 
whereas eicosatrienoic and eicosapentaenoic acids increased with $\mathrm{QTE}_{30}$. Hence, we suggest that increasing concentrations of these FA in milk can primarily be explained by increased hepatic synthesis due to higher availability of their precursors LA and $\alpha$-LNA, which escaped from ruminal BH. Similarly, Turner et al. (2005) reported higher concentrations of eicosapentaenoic acid in the milk fat of Friesian cows fed Lotus corniculatus as a source of condensed tannins, which was related to a higher concentration of the precursor $\alpha$-LNA. The increments of LA and $\alpha$-LNA concentrations in the milk fat of the present study were substantial $\left(\mathrm{QTE}_{15}\right.$ $=10$ and $6.1 \% ; \mathrm{QTE}_{30}=28$ and $25 \%$, respectively) compared to CON. The latter indicates a considerable inhibition of the first isomerization steps of ruminal $\mathrm{BH}$ and an improvement of the milk quality by QTE. Ruminal BH of LA results in RA as the first intermediate (Corl et al., 2001), which may escape ruminal BH and appear in the milk or be further hydrogenated to VA in the rumen. Rumenic acid is an important CLA considered to be essential for humans. Unfortunately, the concentration of RA in the milk was reduced with QTE treatments compared to CON $\left(\mathrm{QTE}_{15}=8.3 \%\right.$ and $\mathrm{QTE}_{30}=16 \%$ ), probably by inhibiting the ruminal BH of LA to RA. The second source of RA is the endogenous synthesis catalyzed by stearoyl Co-A desaturase enzyme (SCD, also called $\Delta^{9}$-desaturase) activity in the mammary gland from ruminally derived VA (Corl et al., 2001; Mosley et al., 2006; Buccioni et al., 2015), a pathway that has been estimated to account for 64 to $97 \%$ of the total RA in milk fat (Griinari et al., 2000; Shingfield et al., 2010). Therefore, reduction of VA in the rumen was probably the main driving factor in reducing $\mathrm{RA}$ in the milk. The desaturase index (DI C14) - used as a proxy for SCD activity (Griinari et al., 2000) - was lower with than without QTE feeding, indicating reduced $\Delta^{9}$-desaturase activity probably caused by QTE supplementation. The latter may additionally support the reduction of RA in the milk. However, extrapolating these results has to be done with caution because desaturase indices (e.g., DI C14) are only an indicator of $\Delta^{9}$-desaturase activity. Moreover, effects of tannins on $\Delta^{9}$-desaturase activity are contradictory in the literature and still need further investigation (Buccioni et al., 2015) to make final conclusions. On one hand, phenols of QTE are hypothesized to be absorbed from the digestive tract (Makkar, 2003), affecting lipid metabolism in the liver or other tissues that is mediated by the low molecular weight simple phenols present in the QTE (Toral et al., 2013). In line with this idea and contrary to our results, Buccioni et al. (2015) reported higher DI C14 in ewes fed QTE compared with those that did not receive QTE, suggesting a positive effect of this type of tannin on the activity of SCD, which in turn affected the ratio between substrate and product of the enzyme. Similar results were reported by Vasta et al. (2009b) and Rana et al. (2012) in intramuscular fat of lambs and kids fed QTE and tannins of Terminalia chebula, respectively. In contrast, Francisco et al. (2016) found no linear relationship between expression level of SCD in lambs and the intake of condensed tannins. On the other hand, condensed tannins ingested by ruminants pass the digestive tract without being degraded and absorbed (Makkar et al., 1995; Min et al., 2003); therefore, they are not expected to have any effect on fat metabolism. Consequently, whether QTE af-

Table 5. Concentrations of fatty acid (FA) groups (least squares means \pm SE) in milk fat and desaturase index (DI) in the control diet (CON) and at 2 levels of quebracho tannin extract (QTE, 15 or $30 \mathrm{~g} / \mathrm{kg}$ of DM)

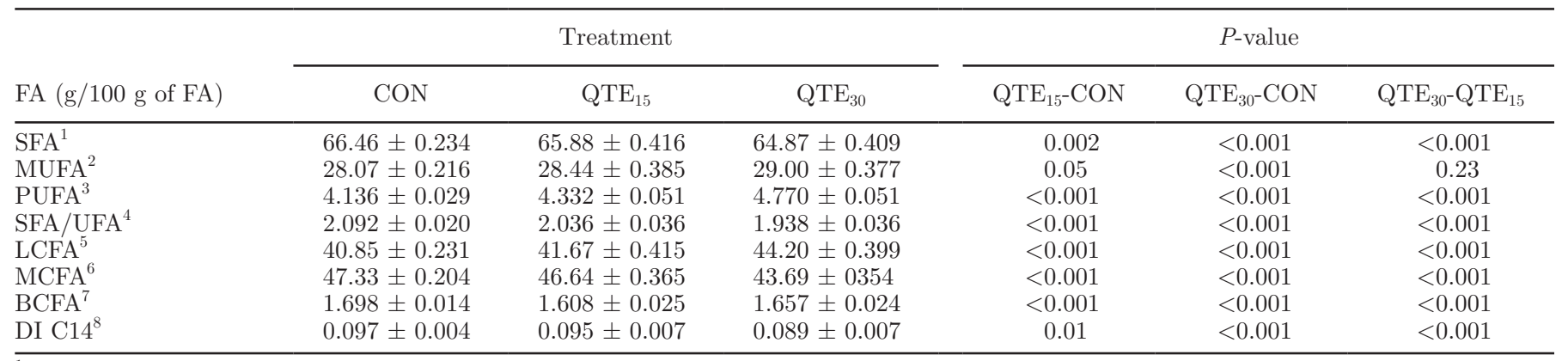

\footnotetext{
${ }^{1}$ Sum of all FA without double bonds.

${ }^{2}$ Sum of all FA with one double bond.

${ }^{3}$ Sum of all FA with more than one double bond.

${ }^{4}$ Unsaturated FA $=$ MUFA + PUFA.

${ }^{5}$ Long-chain FA, C18:0-C24:0 (includes saturated and unsaturated FA).

${ }^{6}$ Medium- to long-chain FA, C11:0-C17:0 (includes saturated and unsaturated FA).

${ }^{7}$ Branched-chain $\mathrm{FA}=$ the sum of iso $\mathrm{C} 14: 0$, iso $\mathrm{C} 15: 0$, iso $\mathrm{C} 16: 0$, iso $\mathrm{C} 17: 0$, anteiso C15:0, anteiso C17:0.

${ }^{8} \mathrm{DI} \mathrm{C} 14=$ cis-9 $\mathrm{C} 14: 1 /(\mathrm{C} 14: 0+$ cis-9 $\mathrm{C} 14: 1)$.
} 
fected $\Delta^{9}$-desaturase activity in the mammary gland or not cannot be certainly defined. If they in fact affected the activity, it cannot be explained with certainty using the existing data in the present study.

The proportions of VA were reduced with both QTE treatments, which may be linked to inhibited $\mathrm{BH}$ of LA and $\alpha$-LNA. Similarly, Minieri et al. (2014) reported decreasing proportions of VA in solid-associated bacteria when fermenting QTE-containing diets caused by a lower extent of BH. However, Buccioni et al. (2015) reported increasing proportions of VA in milk fat of sheep after adding $\sim 53 \mathrm{~g}$ of QTE/ $\mathrm{kg}$ of DM to diets containing soybean oil. Similarly, Khiaosa-Ard et al. (2009) observed that the proportions of VA were higher in an in vitro rumen simulation technique (RUSITEC) essay when diets of hay and linseed oil (i.e., rich in $\alpha$-LNA) were supplemented with condensed tannins of Acacia mearnsii. These contradictory results of increasing concentrations of VA in the milk fat suggest that condensed tannins may inhibit the conversion of VA to SA (Khiaosa-Ard et al., 2009), which represents the last step of ruminal BH of LA (Buccioni et al., 2015). Moreover, in those studies, oils were added to the diets, which increased the ether extract content of diets to 4.6 and $10 \%$ on a DM basis, enhancing the PUFA intake and resulting in larger $\mathrm{BH}$ intermediates such as VA. In contrast, the diets used in our study contained $2.6 \%$ ether extract; therefore, almost the entire low amount of PUFA supplied through the diet was likely biohydrogenated, and the rumen outflow and the flux of VA to the mammary gland was therefore reduced. Considering that tannins inhibited ruminal $\mathrm{BH}$ and reduced VA concentration in milk fat, the SA concentration was expected to be reduced as well. Khiaosa-Ard et al. (2009) and Vasta et al. (2009a) found that condensed tannins inhibited the last step of BH in vitro, where VA is converted to SA. Contrary to these and other studies (Vasta et al., 2009a; Buccioni et al., 2015), the concentration of SA in the milk fat in the present study increased with both QTE treatments compared to CON. Stearic acid is a predominant FA stored in ruminant adipose tissue (Chilliard et al., 2000). Because both QTE dosages lowered the diet digestibility and $\mathrm{QTE}_{30}$ reduced the milk yield of cows (Henke et al., 2017), energy supply to the animals was probably reduced. Hence, increasing concentrations of SA in milk fat of cows receiving 15 and $30 \mathrm{~g}$ QTE $/ \mathrm{kg}$ DM can be speculated to be due to mobilization of body fat (Stoop et al., 2009) caused by a slightly negative energy balance. Oleic acid concentration in the milk increased with each increasing level of QTE in the diet compared to CON, which is in line with Buccioni et al. (2015). Because of co-elutions of C18:1 isomers during total FA analysis, a relatively small imprecision occurred with respect to OA. The overlap of OA with trans-12-14 C18:1 led to a slight overestimation of OA by $2.5 \%$, based on an average milk fat composition $(<1.0 \mathrm{~g} / 100 \mathrm{~g}$ of FA). Overall, however, the changes observed for OA in our experiment are clearly not due to the variation of the trans-12-14 C18:1 fraction. Hence, the overlap should not significantly impair the OA findings. One source of $\mathrm{OA}$ in the milk is the desaturation of SA to OA, which is based on the introduction of a cis double-bond between $\mathrm{C} 9$ and $\mathrm{C} 10$ and is catalyzed by $\Delta^{9}$-desaturase in the mammary gland. Additionally, OA is the most predominant FA in ruminant adipocytes that can be mobilized during a negative energy balance. Therefore, increased concentrations of OA by QTE may also be speculated to be a direct result of mobilized body fat or of desaturation of SA from body fat to OA in the mammary gland. However, OA in milk fat originates in part directly from the diet (Mosley et al., 2002). In this study, the basal diet was characterized by a high content of OA ( $27 \%$ of total FA). Therefore, an increase of OA in the milk fat with each level of QTE may also indicate reduced ruminal $\mathrm{BH}$ of dietary OA. However, the increment of $\mathrm{OA}$ in the milk was only about 2.5 and $6.7 \%$ with $\mathrm{QTE}_{15}$ and $\mathrm{QTE}_{30}$ compared with $\mathrm{CON}$, respectively.

Feeding $\mathrm{QTE}_{15}$ and $\mathrm{QTE}_{30}$ increased the proportions of PUFA and MUFA, whereas the proportions of SFA (especially those of MA and PA) decreased. The latter supports the fact that under the conditions of our experiment, quebracho tannin was able to modulate lipid metabolism in the rumen. Additionally, both QTE dosages increased the proportions of LCFA in milk fat. Some studies have proved the effect of negative energy balance or lactation stage on increased proportion of LCFA (Stoop et al., 2009; Gross et al., 2011). In general, a specific reason for increased SA, OA, and LCFA in the milk with QTE treatments is unclear in this study and probably remains masked by fat mobilization. Nevertheless, it must be remarked that reduction of milk yield and diet digestibility due to QTE supplementation reported by Henke et al. (2017) does not necessarily mean a negative energy balance, which is just speculative. Therefore, interpretations of this aspect should be carefully considered. Thus, fat mobilization can be considered as having played a subordinate role in the concentrations of FA in the milk fat. Consequently, results of this experiment can be predominantly attributed to the effect of QTE on rumen fermentation, microbial activity, and modulation of ruminal BH. The latter was clearly reflected by the reduction of purine derivates in urine (Henke et al., 2017). Additionally, negative effects on in vitro microbial activity was showed by Castro- 
Montoya et al. (2017) in samples of the same diets used in this experiment, and these results were based on reduced total gas production, total volatile $\mathrm{FA}$, and ammonia-N. Furthermore, odd- and branched-chain FA in milk are largely derived from rumen bacteria and are therefore an important marker of rumen function and microbial synthesis (Fievez et al., 2012). Consequently, the reduced BCFA content in the milk supports the detrimental effect of QTE on rumen microbial activity as well. In fact, in a more specific study about the relationship of odd- and branched-chain FA in the milk and quebracho tannin supplementation, we suggested that the highest dosage of QTE reduced duodenal flow of microbial mass (Castro-Montoya et al., 2016). In general, the addition of QTE to diets of dairy cows has the potential to increase to some extent the nutritional quality of milk fat in human diets in terms of LA and $\alpha$-LNA. This conclusion was additionally supported by the reduction of $\mathrm{MA}$ and $\mathrm{PA}, \mathrm{FA}$ that are recognized to increase high-density lipoprotein in humans, accompanied with an increment of total PUFA and LCFA. Feeding strategies attempting to improve quality of ruminant food sources should be considered only when negative effects on any other traits are excluded. Unfortunately, evidence of a reduced concentration of cis-9, trans-11 CLA and VA was observed when QTE was added to the diets, which might outweigh the benefits. Because QTE influenced the FA profile of milk fat both positively and negatively, further research is still needed before concluding that QTE may improve the quality of milk fat of cows.

\section{CONCLUSIONS}

The addition of QTE to diets for lactating dairy cows modulates the FA profile of milk fat through inhibition of ruminal BH. The effects of QTE were dose dependent. On one hand, inhibition of ruminal BH by QTE improved the milk quality. The concentrations of LA and $\alpha$-LNA were increased, and these FA are desirable because of their potential properties in promoting human health. Total PUFA and LCFA in milk fat were increased with each increasing level of QTE in the diets. Although PUFA increments were significant, they were low in quantity. Moreover, concentrations of MA and PA, which are recognized to increase high-density lipoprotein in humans, were reduced to some extent with the highest dosage of QTE. On the other hand, QTE negatively influenced the milk quality by reducing the concentration of cis-9, trans-11 CLA (RA) and VA in the milk, which are important human health promoters. Therefore, further research is needed before concluding that QTE may improve the nutritional quality of cow milk fat human diets.

\section{ACKNOWLEDGMENTS}

This study was funded by the Federal Ministry of Education and Research within the research project "Food Chain Plus" (project number 0315538A; 2010-2015). The authors are very grateful for the support of Ina Köhling and Maike Meeder during sample collection. We gratefully acknowledge the skillful support of the staff of the experimental farm Schädtbek of the Max Rubner-Institute for performing the feeding trial. Additionally, the authors are very grateful for the valuable laboratory work of Melanie Selk, Annette Hollmann, Monika Paschke-Beese, Wiebke Kühl, and Jessica Koch of the Institute of Animal Nutrition and Physiology of the Christian-Albrechts-Universität zu Kiel.

\section{REFERENCES}

Ahnert, S., U. Dickhoefer, F. Schulz, and A. Susenbeth. 2015. Influence of ruminal quebracho tannin extract infusion on apparent nutrient digestibility, nitrogen balance, and urinary purine derivatives excretion in heifers. Livest. Sci. 177:63-70.

Benchaar, C., and P. Y. Chouinard. 2009. Short communication: Assessment of the potential of cinnamaldehyde, condensed tannins, and saponins to modify milk fatty acid composition of dairy cows. J. Dairy Sci. 92:3392-3396.

Buccioni, A., M. Pauselli, C. Viti, S. Minieri, G. Pallara, V. Roscini, S. Rapaccini, M. Marinucci, P. Lupi, G. Conte, and M. Mele. 2015. Milk fatty acid composition, rumen microbial population, and animal performances in response to diets rich in linoleic acid supplemented with chestnut or quebracho tannins in dairy ewes. J. Dairy Sci. 98:1145-1156.

Castro-Montoya, J., A. Henke, J. Molkentin, K. Knappstein, A. Susenbeth, and U. Dickhoefer. 2016. Relationship between milk odd and branched-chain fatty acids and urinary purine derivatives in dairy cows supplemented with quebracho tannins - A study to test milk fatty acids as predictors of rumen microbial protein synthesis. Anim. Feed Sci. Technol. 214:22-33.

Castro-Montoya, J., E. Westreicher-Kristen, A. Henke, M. Diaby, A. Susenbeth, and U. Dickhoefer. 2017. In vitro microbial protein synthesis, ruminal degradation and post-ruminal digestibility of crude protein of dairy rations containing quebracho tannin extract. J. Anim. Physiol. Anim. Nutr. (Berl.) https://doi.org/10.1111/ jpn. 12704.

Chilliard, Y., A. Ferlay, R. M. Mansbridge, and M. Doreau. 2000. Ruminant milk fat plasticity: Nutritional control of saturated, polyunsaturated, trans and conjugated fatty acids. Ann. Zootech. 49:181-205.

Corl, B. A., L. H. Baumgard, D. A. Dwyer, J. M. Griinari, B. S. Philips, and D. E. Bauman. 2001. The role of $\Delta 9$-desaturase in the production of cis-9,trans-11 CLA. J. Nutr. Biochem. 12:622-630.

Dewhurst, R., K. Shingfield, M. Lee, and N. Scollan. 2006. Increasing the concentrations of beneficial polyunsaturated fatty acids in milk produced by dairy cows in high-forage systems. Anim. Feed Sci. Technol. 131:168-206.

DGF (Deutsche Gesellschaft für Fettwissenschaft). 2015. Deutsche Einheitsmethoden zur Untersuchung von Fetten, Fettprodukten, Tensiden und verwandten Stoffen. Wissenschaftliche Verlagsgesellschaft mbH, Stuttgart, Germany.

Fievez, V., E. Colman, J. M. Castro-Montoya, I. Stefanov, and B. Vlaeminck. 2012. Milk odd- and branched-chain fatty acids as biomarkers of rumen function-An update. Anim. Feed Sci. Technol. 172:51-65.

Francisco, A., S. P. Alves, P. V. Portugal, V. M. R. Pires, M. T. Dentinho, C. M. Alfaia, E. Jerónimo, J. A. M. Prates, J. SantoSilva, and R. J. B. Bessa. 2016. Effect of feeding lambs with a tan- 
niferous shrub (rockrose) and a vegetable oil blend on fatty acid composition of meat lipids. Animal 10:2061-2073.

Griinari, J. M., B. A. Corl, S. H. Lacy, P. Y. Chouinard, K. V. V. Nurmela, and D. E. Bauman. 2000. Conjugated linoleic acid is synthesized endogenously in lactating dairy cows by $\Delta^{9}$-desaturase. J. Nutr. 130:2285-2291.

Gross, J., H. A. van Dorlad, R. M. Bruckmaier, and F. J. Schwarz. 2011. Milk fatty acid profile related to energy balance in dairy cows. J. Dairy Res. 78:479-488.

Henke, A., U. Dickhoefer, E. Westreicher-Kristen, K. Knappstein, J. Molkentin, M. Hasler, and A. Susenbeth. 2017. Effects of quebracho tannin extract on feed intake, digestibility, excretion of urinary purine derivatives and milk production in lactating dairy cows. Arch. Anim. Nutr. 71:37-53.

Hothorn, T., F. Bretz, and P. H. Westfall. 2008. Simultaneous inference in general parametric models. Biom. J. 50:346-363.

IDF (International Dairy Federation). 2002a. Milk fat-Preparation of fatty acid methyl esters: ISO 15884-IDF 182. IDF, Brussels, Belgium.

IDF (International Dairy Federation). 2002b. Milk fat-Determination of the fatty acid composition by gas-liquid chromatography: ISO 15885-IDF 184. IDF, Brussels, Belgium.

IDF (International Dairy Federation). 2010. Milk-Determination of fat content-Gravimetric method (Reference method): ISO 1211IDF 1. IDF, Brussels, Belgium.

Jones, G. A., T. A. McAllister, A. D. Muir, and K. Cheng. 1994. Effects of sainfoin (Onobrychis viciifolia Scop.) condensed tannins on growth and proteolysis by four strains of ruminal bacteria. Appl. Environ. Microbiol. 60:1374-1378.

Khiaosa-Ard, R., S. F. Bryner, M. R. L. Scheeder, H. R. Wettstein, F. Leiber, and M. Kreuzer. 2009. Evidence for the inhibition of the terminal step of ruminal $\alpha$-linolenic acid biohydrogenation by condensed tannins. J. Dairy Sci. 92:177-188.

Kronberg, S. L., E. J. Scholljegerdes, G. Barceló-Coblijn, and E. J. Murphy. 2007. Flaxseed treatments to reduce biohydrogenation of alpha-linolenic acid by rumen microbes in cattle. Lipids 42:11051111.

Makkar, H. P. S. 2003. Effects and fate of tannins in ruminant animals, adaptation to tannins, and strategies to overcome detrimental effects of feeding tannin-rich feeds. Small Rumin. Res. 49:241-256.

Makkar, H. P. S., K. Becker, H. J. Abel, and C. Szegletti. 1995. Degradation of condensed tannins by rumen microbes exposed to quebracho tannins (QT) in rumen simulation technique (RUSITEC) and effects of QT on fermentative processes in the RUSITEC. J. Sci. Food Agric. 69:495-500.

Månsson, H. L. 2008. Fatty acids in bovine milk fat. Food Nutr. Res. $52: 1-3$.

Min, B., T. Barry, G. Attwood, and W. McNabb. 2003. The effect of condensed tannins on the nutrition and health of ruminants fed fresh temperate forages: A review. Anim. Feed Sci. Technol. $106: 3-19$
Minieri, S., A. Buccioni, S. Rapaccini, A. Pezzati, D. Benvenuti, A. Serra, and M. Mele. 2014. Effect of quebracho tannin extract on soybean and linseed oil biohydrogenation by solid associated bacteria: An in vitro study. Ital. J. Anim. Sci. 13:604-608.

Mosley, E. E., G. L. Powell, M. B. Riley, and T. C. Jenkins. 2002. Microbial biohydrogenation of oleic acid to trans isomers in vitro. J. Lipid Res. 43:290-296.

Mosley, E. E., B. Shafii, P. J. Moate, and M. A. McGuire. 2006. Cis-9, trans-11 conjugated linoleic acid is synthesized directly from vaccenic acid in lactating dairy cattle. J. Nutr. 136:570-575.

Mueller-Harvey, I. 2006. Unravelling the conundrum of tannins in animal nutrition and health. J. Sci. Food Agric. 86:2010-2037.

Porter, L. J., L. N. Hrstich, and B. G. Chan. 1986. The conversion of procyanidins and prodelphinidins to cyanidin and delphinidin. Phytochemistry 25:223-230.

Rana, M. S., A. Tyagi, S. A. Hossain, and A. K. Tyagi. 2012. Effect of tanniniferous Terminalia chebula extract on rumen biohydrogenation, $\Delta^{9}$-desaturase activity, CLA content and fatty acid composition in longissimus dorsi muscle of kids. Meat Sci. 90:558-563.

Salem, N. Jr., R. Pawlosky, B. Wegher, and J. Hibbeln. 1999. In vivo conversion of linoleic acid to arachidonic acid in human adults. Prostaglandins Leukot. Essent. Fatty Acids 60:407-410.

Schaarschmidt, F., and L. Vaas. 2009. Analysis of trials with complex treatment structure using multiple contrast tests. Hortic. Sci. (Prague) 44:188-195.

Shingfield, K. J., L. Bernard, C. Leroux, and Y. Chilliard. 2010. Role of trans fatty acids in the nutritional regulation of mammary lipogenesis in ruminants. Animal 4:1140-1166.

Smith, A. H., E. Zoetendal, and P. I. Mackie. 2005. Bacterial mechanisms to overcome inhibitory effects of dietary tannins. Microb. Ecol. 50:197-205.

Stoop, W. M., H. Bovenhuis, J. M. L. Heck, and J. A. M. van Arendonk. 2009. Effect of lactation stage and energy status on milk fat composition of Holstein-Friesian cows. J. Dairy Sci. 92:1469-1478.

Toral, P. G., G. Hervás, A. Belenguer, E. Bichi, and P. Frutos. 2013 Effect of the inclusion of quebracho tannins in a diet rich in linoleic acid on milk fatty acid composition in dairy ewes. J. Dairy Sci 96:431-439.

Turner, S. A., G. C. Waghorn, S. L. Woodward, and N. A. Thomson. 2005. Condensed tannins in birdsfoot trefoil (Lotus corniculatus) affect the detailed composition of milk from dairy cows. Proc. N Z. Soc. Anim. Sci. 65:283-289.

Vasta, V., H. P. S. Makkar, M. Mele, and A. Priolo. 2009a. Ruminal biohydrogenation as affected by tannins in vitro. Br. J. Nutr. 102:82-92.

Vasta, V., A. Priolo, M. Scerra, K. G. Hallett, J. D. Wood, and O. Doran. 2009b. $\Delta^{9}$-Desaturase protein expression and fatty acid composition of longissimus dorsi muscle in lambs fed green herbage or concentrate with or without added tannins. Meat Sci $82: 357-364$. 